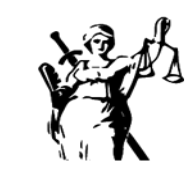

JUSTICIA

ISSN impreso 0124-7441
ISSN digital 2590-4566

\title{
Derechos del artista como trabajador en el marco del fortalecimiento de la industria creativa en Colombia
}

\author{
Rights of the artist as a worker within the framework of the \\ strengthening of the creative industry in Colombia
}

\author{
(iD) \\ Jorge Wilches Visbal \\ Universidad del Magdalena, Colombia \\ jhwilchev@gmail.com
}

\author{
(iD) \\ Sandra Djordjevic \\ Universidad de Belgrado \\ Sandra.djordjevi@rocketmail.com
}

Yarlemis Loraine Cohen Rodriguez

Universidad del Magdalena, Colombia

ycohen@unimagdalena.edu.co

Recibido: 25 de agosto de 2020 / Aceptado: 26 de enero de 2021

https://doi.org/10.17081/just.26.39.4417

\section{Resumen}

El presente artículo propone una reflexión acerca de la situación de los derechos de los artistas cuando se desempeñan como trabajadores o prestadores independientes de servicios dentro de la industria creativa en Colombia, para lo que se revisan los conceptos de empleado y trabajador, así como las de artista profesional y aficionado desde una perspectiva legal y doctrinal. De igual forma se revisa el cuerpo normativo de la industria creativa en Colombia como apuesta para la generación de empleo y desarrollo. Por último, se proponen algunas sugerencias de protección e incentivo laboral de la profesión de artista a ejemplo de la recién promulgada Ley del Actor.

PALABRAS CLAVE: Artista, trabajador, prestador de servicios, industria creativa, Ley del Actor.

\begin{abstract}
This paper proposes a reflection on the situation of the artists' rights in the cases when they act as workers or independent service providers within the creative industry in Colombia, for which the concepts of employee and worker as well as the concepts of professional and amateur are reviewed from a legal and academic perspective. Likewise, it reviews the legal body on the creative industry in Colombia as a bet for the generation of employment and development. Lastly, certain suggestions for an enhanced protection and work incentives for the artist as a profession are proposed, following the example of the recently enacted Actor Act.
\end{abstract}

KEYWORDS: Artist, worker, independent service provider, creative industry, Actor Act.

Como Citar: Wilches Visbal, J., Djordjevic, S., \& Cohen Rodriguez, Y. L. (2021). Derechos del artista como trabajador en el marco del fortalecimiento de la industria creativa en Colombia. Justicia, 26(39), 273-284. https://doi.org/10.17081/just.26.39.4417 


\section{Introducción}

La creación de empleo en el sector cultural ha sido una de las respuestas que los países han dado frente al incremento en los niveles de desempleo estructural (Throsby, 2001), dirigiendo la atención especialmente hacia el rol central de los artistas como productores o proveedores de contenido de la industria en cuestión.

Se considera incluso que las industrias creativas brindan mejores y más atractivas oportunidades a los jóvenes en lo que tiene que ver con el desarrollo de estrategias que involucran el manejo de nuevas tecnologías, permitiendo que los procesos de innovación puedan traducirse en generación de empleo y mejoramiento de la calidad de vida (FEDESARROLLO, 2019).

En el caso de Estados Unidos, el Proyecto de Industrias Creativas reportó que en 2006 más de 548.000 negocios del arte emplearon 2.9 millones de trabajadores, lo cual constituía el $4.3 \%$ de todos los negocios del país (Lena \& Lindemann, 2014).

Los países latinoamericanos, por su parte, han ido avanzando hacia la superación de la tendencia que buscaba defenderse de la amenaza de la invasión de las industrias culturales extranjeras a través de una estrategia meramente discursiva o teórica, para pasar a la apuesta del fortalecimiento y difusión de los contenidos propios.

En Colombia, el interés por desarrollar, fomentar, incentivar y proteger las industrias creativas se ha visto materializado inicialmente en la promulgación de la Ley 1834 de 2017, al considerar que este sector de la economía genera empleo de calidad, es motor de desarrollo y fomenta el tejido social y humano, así como la identidad y equidad (Art. 3o).

La misma norma define en su artículo 20 que las industrias creativas "son aquellas que comprenden los sectores que conjugan creación, producción y comercialización de bienes y servicios basados en contenidos intangibles de carácter cultural, y/o aquellas que generen protección en el marco de los derechos de autor".

Sin embargo, dado que la normativa indicada no establece quiénes deben ser considerados como artistas o autores, este artículo propondrá la utilización por analogía de las definiciones existentes en instrumentos afines, tales como la Decisión Andina 351 de 1993.

Así mismo, teniendo en cuenta que uno de los mayores retos que enfrentan las industrias creativas en esta parte del continente, según los estudios realizados por el Banco Interamericano de Desarrollo -BID-, es el fortalecimiento de las condiciones laborales de los involucrados (FEDESARROLLO, 2019), el presente artículo propone una reflexión acerca del rol desempeñado por los artistas y autores como principales proveedores de contenidos de las industrias creativas con el fin de conocer cuál es la situación de los mismos en relación con sus derechos cuando se desempeñan como trabajadores o prestadores independientes de servicios a la luz de la normatividad aplicable y el desarrollo doctrinal pertinente.

A su vez, este artículo se adentra en la problemática de la condición-suficiente para que un individuo sea reconocido como artista en el contexto del desarrollo formal del arte en Colombia.

Para ello, se abordará en primer lugar una revisión de los conceptos de empleado, trabajador, ocupación laboral y artista por fuera de los límites de la legislación nacional; luego se presentará un examen de las categorías de artistas propuestas por Throsby para pasar de ahí a los desafíos de la industria creativa en relación con los artistas en Colombia. 


\section{Revisión de conceptos relacionados}

El concepto de empleado ha sido reemplazado en casos puntuales1 con relativo éxito por el de trabajador, al considerar que con frecuencia las regulaciones concernientes a la protección de derechos laborales se interpretan de forma ultra restrictiva y se excluye de tal protección a aquellos que, a pesar de ser dependientes económicamente de un determinado empleador, conservan cierta discrecionalidad en el ejercicio de su actividad (Davidov, 2005).

Para Davidov (2005, p. 58), el término trabajador comprende tanto a los individuos que hacen parte de una relación laboral regida por un contrato de trabajo, como aquellos que trabajan bajo cualquier otra modalidad contractual "por la que se comprometen a realizar personalmente o prestar un servicio en favor de otra parte".

En legislaciones como las del Reino Unido, el examen que permite determinar si un individuo es un empleado o un trabajador se basa en el diagnóstico de la cantidad de independencia que éste maneja, no en lo que respecta al control del propio tiempo y la toma de decisiones, sino en la capacidad de distribuir el riesgo de su actividad entre las diversas relaciones contractuales que posea (Davidov, 2005).

Sin embargo, en lo que respecta a legislación colombiana, el artículo 23 del Código Sustantivo del Trabajo consagra que la continuada subordinación sí es elemento esencial para la existencia del contrato de trabajo, la cual es tenida como sinónima de la dependencia del trabajador respecto del empleador, sin mayor distinción en cuanto al tipo de dependencia que se trata.

Adicionalmente, el artículo 24 de la referida norma dispone que el contrato de trabajo regirá todas las relaciones de trabajo personal, por lo que, en el contexto de la legislación colombiana, las distinciones entre empleado y trabajador parecerían ser inaplicables si no, inexistentes. No obstante, dada la naturaleza de su actividad, el término trabajador resulta más apropiado para referirse a los artistas en las circunstancias en las que se les llamaría empleados.

En cuanto a la noción de ocupación laboral, ésta se ha diferenciado de la noción de empleo que, en tanto formal y garantizado por los principios de seguridad social, es un tipo específico de trabajo estable asalariado, el cual es con frecuencia tenido como tradicional e inviable por el costo adicional que genera para el empleador (Gomes \& Elizalde, 2009).

De lo anterior se desprende que, en circunstancias específicas, esta opción es sustituida por categorías más flexibles, tales como las de, trabajo temporal, trabajo autónomo o por cuenta propia, prestación de servicios y subempleo, entre otras que son también llamadas ocupaciones. Se ha considerado que los efectos de la globalización, las consecuencias del avance tecnológico que permiten el relevo de algunas operaciones del trabajo humano por la máquina, y la reducción de los puestos de trabajo del aparato estatal como estrategia para aminorar el gasto público, agravan la situación de los trabajadores, que sin las garantías de la formalidad del empleo, quedan a exclusiva disposición de los intereses variables del mercado (Gomes \& Elizalde, 2009).

No obstante, los trabajadores de la industria cultural, también conocida como industria creativa, pueden llegar a verse beneficiados de las situaciones antes mencionadas dada la naturaleza del sector en el que participan. A esto se suma que, mientras que los motivos financieros son determinantes para la mayoría de los trabajadores en el proceso de decisión sobre una oferta de trabajo, para los investigadores, académicos y artistas, la decisión suele tener una influencia no pecuniaria (Throsby, 1992). En esta medida,

Reino Unido, Alemania y Canadá. 
los autores y artistas al servicio de la industria creativa empiezan a ser considerados como aliados para el fortalecimiento de las economías nacionales tanto de los países desarrollados como de los países en vía de desarrollo.

Así las cosas, es necesario revisar que según la Decisión 351 de 1993 expedida por la Comunidad Andina de Naciones sobre obras artísticas, científicas y literarias, autor es la persona física que realiza la creación intelectual y artista intérprete o ejecutante es la persona que representa, canta, lee, recita, interpreta o ejecuta en cualquier forma una obra (Art. 2). Sin embargo, en adelante se utilizará el término artista para referirse al autor y al intérprete indistintamente como lo propone Lena \& Lindemann (2014, p. 75).

Conviene por tanto reconocer en el vocablo artistas a aquellos trabajadores que se perciben a sí mismos y son percibidos por otros como productores de objetos artísticos e ideas. Estos pueden ser: músicos, bailarines, actores, pintores, escultores, poetas, novelistas, compositores, entre otros; y también los trabajadores relacionados con el arte tales como dramaturgos, directores de teatro, escenógrafos, curadores y más, quienes, a través de su actividad creativa, la cual realizan por iniciativa propia o a petición de otra parte, contribuyen a revitalizar industrias, sectores y ciudades (Lena \& Lindemann, 2014).

\section{Examen de las categorías de artistas propuestas por Throsby}

Con el fin de aproximarse a un análisis del rol del artista en la consolidación de la industria creativa es necesario revisar la distinción que aporta Throsby entre la práctica de los profesionales y la de los aficionados del arte. Esto debido a que, según el autor, son los profesionales los que contribuirán más efectivamente hacia la producción de obras de valor artístico perdurable (Throsby, 2001), lo que sin duda tendrá implicaciones en el sector económico.

Es posible sugerir que tal idea obedece a que, en las artes, aquellos que ostentan un estatus de profesionales suelen estar considerablemente comprometidos a alcanzar ciertos estándares en sus obras de forma que puedan ser juzgadas como aceptables por un amplio e indistinto grupo de críticos. Es decir, el artista dedica su fuerza productiva a hacer que la obra sea reputada como competitiva dentro del mercado de su interés.

Aunado a lo anterior, Throsby (2001) sugiere que el sub-grupo de artistas que pueden ser llamados como practicantes profesionales debe caracterizarse también porque a) cuente con cualificaciones educativas apropiadas, así como suficiente experiencia de entrenamiento formal; b) dedique una cantidad de tiempo mínima al trabajo creativo dentro de un periodo específico; c) cuente con asociación o membresía a algún grupo que lo acredite o d) perciba ciertos niveles de ingresos por su trabajo artístico.

En otra ocasión, el autor utilizó las categorías de semiprofesionales y aficionados serios para referirse a quienes suelen estar comprometidos con alcanzar altos estándares en sus obras y a recibir pagos de forma ocasional pero cuya principal actividad laboral suele ser cualquier otra (Throsby \& Ginsburgh, 2014). Esto implica que muchos de estos artistas se verian obligados a desarrollar trabajos por fuera de las artes con el fin de obtener los ingresos necesarios para la subsistencia y continuidad en la práctica de su arte (Throsby, 1992).

En el escenario colombiano, la aplicación de las condiciones mencionadas para determinar qué artistas deben ser considerados profesionales demanda cierta flexibilidad, pues basta revisar la historia para reconocer que sólo hasta 1877 la enseñanza de las artes y oficios se convirtió en un clamor nacional tal como consta en artículo periodístico de la época: 
Aquí en nuestro país, donde la ignorancia i la miseria constituyen la única herencia positiva de la mayor parte de las clases sociales; donde los hábitos i las ciegas rutinas forman una barrera contra la cual se estrella en balde el empuje del espíritu de progreso, de por sí irresistible; donde ahora no más estamos haciendo, tímidamente, los primeros ensayos para valernos por nosotros mismos, juzgamos de grande importancia la fundación de escuelas de artes i oficios, que impulsen estos ramos hácia el desarrollo a que les llaman los copiosos elementos con que la industria ha de contribuir en breve al bienestar general (Vásquez, 2014, p. 37).

Las razones subyacentes a tal pretensión generalizada en aquella época pudieron haber estado en la misma línea del argumento más tarde planteado por Throsby, para quien la estimación de artistas como profesionales está supeditada al hecho de que los mismos cuenten con cualificaciones académicas pertinentes. Aún más, tal como se evidencia, existe una estrecha relación entre la valoración de la enseñanza de las artes y la consolidación de un mejor proyecto de sociedad, lo cual debía ser una aspiración primordial para un pueblo que había empezado a asumir las consecuencias de su independencia.

No obstante, el Arte, al no ser considerado como una profesión socialmente aceptada en la sociedad colombiana del siglo XIX tuvo que transitar un camino dispendioso hasta llegar a ser incluido como materia de estudio en la educación superior en la Escuela Nacional de Bellas Artes en 1886 (Vásquez, 2014). De tal forma, que la reciente formalización de la oferta de la enseñanza de las artes resulta en que sea inconveniente exigir de los artistas colombianos una estricta formación y experiencia académica para que los profesionales se distingan de los aficionados.

Esto queda reflejado en el artículo 1 del Decreto 2166 de 1985 por el cual se crea el Fondo de Seguridad Social del Artista Colombiano, al señalar que "son profesionales del arte los artistas, empíricos o académicos, que demuestren que han ejercido, o ejercen, actividades inherentes al arte en cualquiera de sus distintas expresiones."

Así mismo, la asociación o pertenencia a grupos que acrediten la condición de artistas es una de las consecuencias de un relativamente reciente proceso de transformación del arte colombiano, originado desde mediados del siglo XX a partir de la democratización y posicionamiento de la clase media, luego orientada hacia los sectores estudiantiles y obreros (Aldana, 2014).

Precisamente en el marco del proceso de consolidación de la identidad colombiana han ido surgiendo las figuras más emblemáticas del arte local, sea porque han personificado los valores de la nación, sea porque han visibilizado las inconformidades, costumbres u otras realidades de la base social2.

Por ejemplo, a pesar de que para la Europa de los siglos XVII y XVIII, con gran influencia en el Nuevo Mundo, la representación pictórica de la familia como estructura social fundamental era un tema primordial, tal como queda evidenciado en las obras de Velásquez, Murillo y Goya; en Colombia, sin embargo, los retratos de la familia no interesaron a los pintores nacionales sino a partir del siglo XIX, pues durante la época colonial la pintura en Colombia prestaba un servicio casi exclusivamente religioso (Rodríguez, 2015).

2 "Tal como se ha dicho, la pintura estaba muy sujeta a los modelos que procedían de Europa. Gradualmente los artistas posteriores a la Independencia comenzaron a registrar particularidades del país, las gentes, sus actitudes y el medio que los rodeaba" (Fajardo de Rueda, 2000, p. 102). 
"Sagrada Familia del Pajarito".

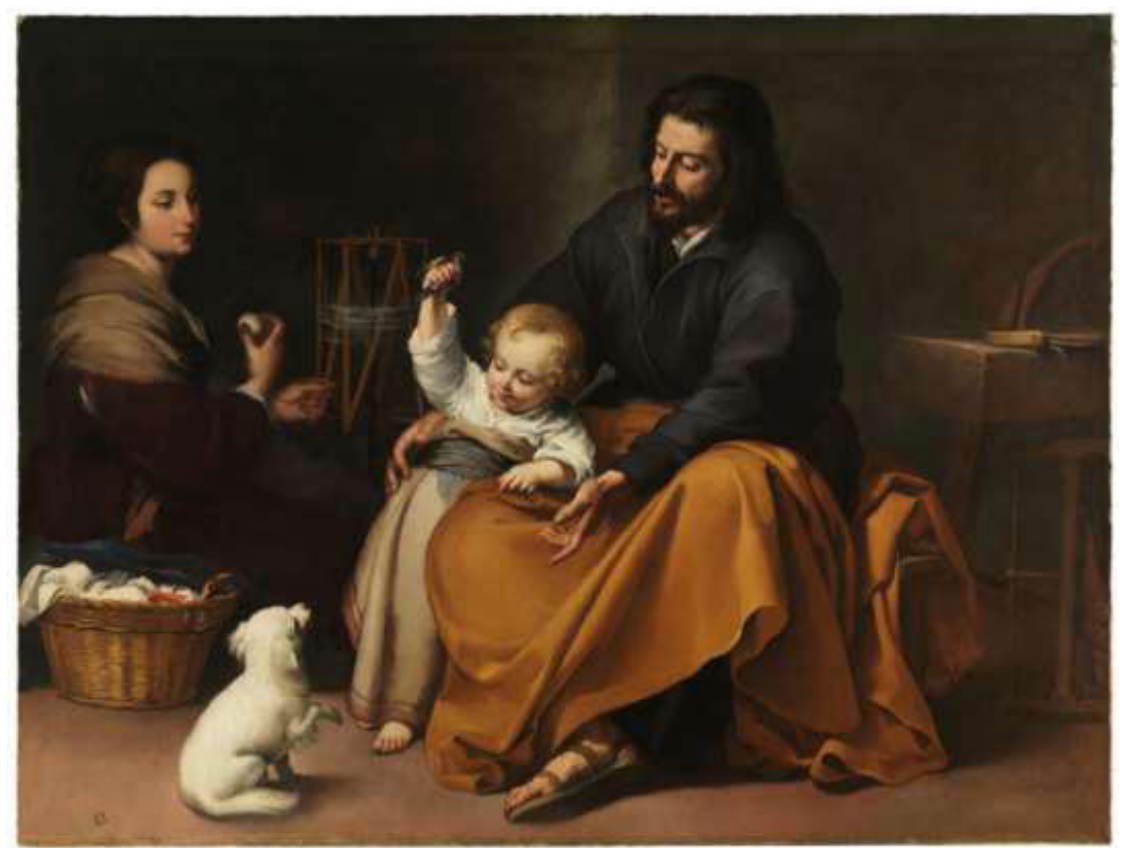

Murillo, Bartolomé Esteban, 1650. Colección Museo del Prado.

Desde ese momento, artistas como Manuel Dositeo Carvajal, Ramón Torres Méndez, José María Espinosa Prieto, entre otros, inmortalizaron escenas cotidianas de sus propias familias, de las familias de la nobleza, de niños, ancianos y grupos populares hasta el momento ignorados en las artes visuales del país o retrataron modelos ideales de familia a los que aspiraba gustosa la mayoría de la población.

De Manuel D. Carvajal se cree que fue autodidacta3 en su aprendizaje del Arte y que dedicó toda su vida también al estudio de las ciencias naturales. De igual forma se puede afirmar que su posición política, al ser cuñado del general José María Obando, Presidente de la República de Colombia, y la riqueza de su familia proveniente de la explotación de oro y plata, facilitaron su actividad artística en cuanto a la posibilidad de contar con recursos de buena calidad, con algunas excepciones como cuando el General Obando se excusó por no haberle podido mandar pinceles, marfil y libros para su labor como profesor de arte y dibujo en colegios e internados durante su exilio en Chile4.

3 "Son muy pocos los datos que se han podido recoger sobre la época de su formación. No se sabe quiénes fueron sus maestros o si estudió en alguna institución conocida. Tampoco se tiene conocimiento sobre cuáles fueron los estudios que lo iniciaron en el arte" (Fajardo de Rueda, 2000, p. 102).

4 En el año 1842, el general Obando, perseguido por sus enemigos políticos se vio obligado a exiliarse en Perú, de donde fue expulsado para refugiarse en Chile. Manuel Dositeo llegó allí al poco tiempo en compañía de su hermana, la esposa del general Obando y sus sobrinos. Colaboró con las clases de dibujo y pintura en un colegio para niñas (Fajardo de Rueda, 2000). 
Colección Fondo Cultural Cafetero, Ministerio de Cultura

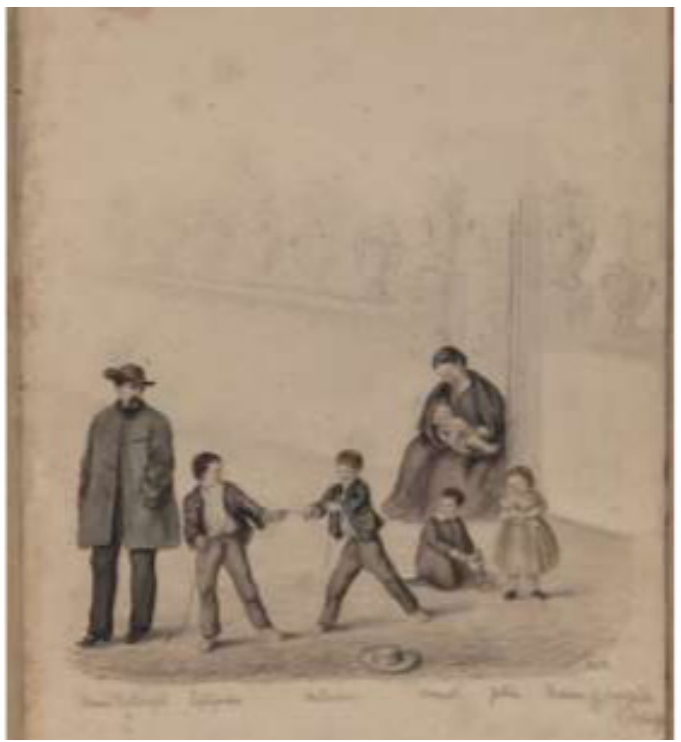

“Manuel d. Carvajal, Epifanio, Antonio, Manuel, Julia, Tomás y Margarita Quijano de Carvajal.” Manuel D. Carvajal, 1862.

Otro artista autodidacta de la historia del arte colombiano fue Ramón Torrez Méndez, vinculado laboralmente desde temprana edad con la impresión tipográfica y relacionado como educador de la Escuela de Artes y Oficios y de la Universidad Nacional, pese a no haber recibido él mismo ninguna instrucción formal (Tarazona, 2016).

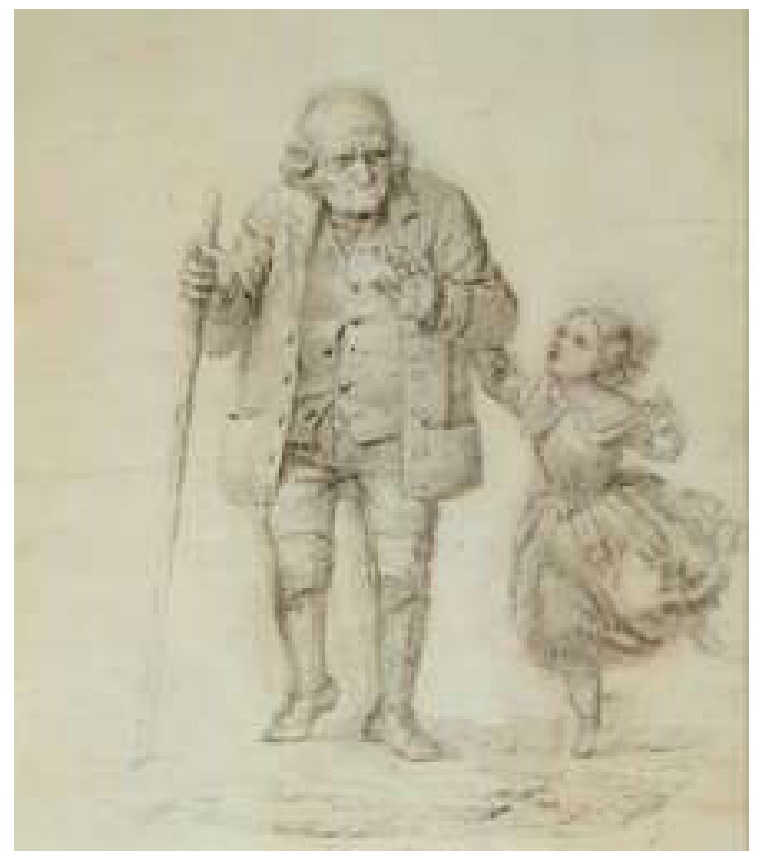

“Sin título." Torrez Méndez, Ramón, 1800-1899 Colección de Arte, Banco de la República. 
Tales ejemplos propios de la colombianidad excepcionan a la fuerza el planteamiento de Throsby, pues, aunque sin cualificaciones educativas o entrenamiento formal, no puede decirse de ellos que fueran semiprofesionales o simplemente aficionados serios.

\section{Desafíos de la industria creativa en relación con los artistas}

El concepto de industria creativa tiene antecedentes en el concepto de industria cultural utilizado por Adorno a partir de 1948 para referirse a las técnicas de producción industrial en la creación y difusión masiva de obras culturales y en el concepto de economía creativa, que entiende la creatividad como motor de innovación que aporta una ventaja significativa para el desarrollo de los negocios (UNESCO, 2010).

Durante los años 90 empezó a utilizarse el término industria creativa para hacer referencia a aquella que, haciendo uso de la creatividad, la destreza y el talento, "tiene potencial de producir riqueza y empleo a través de la generación y explotación de la propiedad intelectual" (UNESCO, 2010).

Esta definición pasó a ser unida a la de industria cultural, incorporándosele otros elementos tales como, la comercialización de bienes, servicios y actividades de contenido cultural, artístico o patrimonial.

Es claro, por tanto, que, dentro de la industria creativa, el capital humano tiene una importancia insustituible, contrario a lo que suele pensarse acerca de otros sectores productivos en los que el trabajo del hombre ha sido reforzado y hasta sustituido por la máquina, análoga o digitalmente; puesto que, según Velasco la creación artística es una facultad específicamente humana que surge con la necesidad del hombre de enfrentarse a la angustia que le ocasiona encarar algo desconocido, intangible o incomprensible (Velasco, 2004).

El autor sostiene que esta vivencia, exclusiva del ser humano, es fisiológicamente una emoción, es decir, un estado subjetivo originado en un sustrato anatómico funcional específico. Así mismo, Jaspers considera que es esencial a la condición humana el hallarse con frecuencia ante situaciones límite como el sufrimiento, la lucha por sobrevivir y la muerte, las cuales le resultan inmodificables. Consciente de su limitación en el espacio y el tiempo, el hombre se vuelve hacia Dios, que es Superior y Trascendente y en algunos casos hace uso del arte para cifrar-descifrar esta relación, que de otra manera sería informulable (Velasco, 2004).

Pese a que Hegel sostiene que "la obra de arte persigue un fin particular que es inmanente en ella" (Muñoz Martínez, 2006, p. 239), podría afirmarse que dicho fin particular existe en el autor e incluso en la audiencia, pero no en la obra, pues es el ser racional, quien a partir de su propia relación con el entorno tangible e intangible dota de sentido y profundidad los contenidos creativos y culturales de una sociedad, conformando a su vez el catálogo de productos de los que se vale la industria creativa para alcanzar sus fines.

Así las cosas, la industria creativa podrá ser tenida como una estrategia efectiva de desarrollo, sólo en la medida en que la creatividad individual sea debidamente incentivada, y en la medida de lo posible, recompensada, lo cual implica, como lo propone Fonseca, encontrar un modelo de economía que una el crecimiento del país y la recompensa a los productores creativos en la misma proporción que se vale de sus esfuerzos (Fonseca Reis, 2008).

Esto es, porque a pesar de la iniciativa de los países de incorporar modelos de economía creativa y consecuentemente permitir la formalización de pequeños negocios y presentar pocas barreras de acceso con miras a la generación de ingresos y trabajo, la realidad demuestra que esto no siempre se traduce en una 
mejor distribución de los ingresos, inclusión socioeconómica, entre otros beneficios esperados. De hecho, tal como se constata en el informe de FEDESARROLLO (2019) la inestabilidad laboral se encuentra asociada a la industria creativa debido al bajo porcentaje de artistas que cuentan con sistemas de protección estatal.

En Colombia, en el marco de la política gubernamental de Economía Naranja, el artista está llamado a ser fundamentalmente también empresario, su propio empleador y empleador de otros, toda vez que los incentivos anunciados en la Ley Naranja (L. 1834 de 2017) y la Ley de Crecimiento Económico5 estarían dirigidos a favorecer la creación de empresa. No obstante, el artista como actor creativo, parece no contar con ningún estímulo individual, quedando a merced de su capacidad de agremiación, lo que no le es siempre exigible dada su personalidad o cualquier otro factor determinante.

En tal sentido, el fomento a la economía creativa que se busca mediante la adopción de la Ley Naranja no se realiza en términos del compromiso estatal que se consagra en el artículo 71 de la Constitución Política, el cual establece que el Estado ofrecerá estímulos especiales a personas e instituciones que ejerzan actividades relacionadas con la ciencia, tecnología y demás manifestaciones culturales, sino que parece valerse de estrategias ya existentes tales como el Programa Nacional de Estímulos6.

Dicho programa se dirige a personas naturales y utiliza el mecanismo de convocatorias públicas anuales, por lo que fuera de tales estímulos eventuales, la situación del artista como trabajador-proveedor de la industria creativa es desventajosa en proporción al aporte que realiza.

Por ejemplo, en caso de que un artista realice una obra en cumplimiento de un contrato de prestación de servicios o de un contrato de trabajo, se presumirá, salvo pacto en contrario, que los derechos patrimoniales sobre la obra han sido transferidos al encargante o empleador. Es decir, el contratante podrá realizar la explotación de la obra sin requerir la autorización del autor durante el plazo pactado teniendo como límite todo el tiempo de vida del artista y 80 años después de su muerte, mientras que el autor recibirá en la mayoría de los casos una única compensación, o si se trata de un trabajador, una compensación periódica a título de salario que no está sujeta a tratamiento tributario exceptivo sin poder reivindicar más que los derechos morales sobre su creación.

Aún más, el pago o abono de los mismos estímulos referidos con anterioridad se encuentra gravado con el impuesto de renta, debido a que no existe disposición normativa que otorgue algún beneficio tributario relacionado con tal actividad.

El más reciente logro en este sentido lo representa la Ley 1975 del 24 de julio de 2019 o Ley del Actor, cuya discusión abrió el debate sobre las condiciones laborales de los actores y actrices en Colombia, entre las cuales conviene destacar las largas jornadas de grabación sin recibir las debidas prestaciones de ley y situaciones relativas a la seguridad social (AIL, 2019). La Ley del Actor estipula la que podría ser la primera medida real de protección de los derechos de los artistas trabajadores de la industria cinematográfica en Colombia, cuyo texto es el que sigue:

Cuando la vinculación de los actores y actrices a una producción sea bajo una modalidad sin dependencia laboral, de carácter individual o asociada, las partes pactarán el tiem-

5 Ley 2010 de 2019, entrada en vigor el 1 de enero de 2020. Tiene como base la Ley 1943 de 2018 o Ley de Financiamiento, la cual fue aprobada por el Congreso de la República de Colombia en el mes de diciembre de 2018 y declarada inexequible por la Corte Constitucional durante el último trimestre del año 2019 al considerar que tenía vicios de trámite, por lo que perdió su vigencia a partir del primero de enero de 2020.

6 “El Ministerio de Cultura, a través del Programa Nacional de Estímulos (en adelante, PNE) tiene como propósito movilizar a los artistas, creadores, investigadores y gestores culturales colombianos, bien sea en el ámbito nacional o internacional, para que en las más diversas disciplinas, reciban a través de becas, Pasantías, premios nacionales, reconocimientos o residencias artísticas un estímulo a su quehacer" (MINCULTURA, 2008). 
po de ejecución del servicio atendiendo el criterio de coordinación, observando como referente un máximo de 12 horas diarias o 72 horas semanales a fin de que el contratista pueda tener espacios de descanso (Art. 9, para 2, L. 1975/2019).

El parágrafo 1 del homónimo artículo, consagra: "En los casos en que la vinculación sea de carácter laboral, se aplicarían las disposiciones del Código Sustantivo del Trabajo”.

En cuanto a los Derechos Patrimoniales de fijación y reproducción, la Ley en cuestión contempla que los actores puedan autorizar la explotación de estos como sea requerido para las producciones audiovisuales en las que participen, pactando una remuneración determinada que se discriminaría de forma independiente a la remuneración por el trabajo o servicio de actuación (Art. 13, para 1, L. 1975/2019).

Sin embargo, los derechos de Comunicación al Público, Distribución o Alquiler Comercial no fueron incluidos en esta disposición, lo que puede significar una victoria parcial para los actores, toda vez que conservan la posibilidad de ejercer algunos Derechos Conexos en virtud de su labor como intermediarios en la divulgación de las obras.

Por lo anterior, se hace necesario que los esfuerzos encaminados al fortalecimiento de la industria creativa en Colombia incluyan las iniciativas que permitan mejorar las condiciones también de los artistas de las disciplinas relacionadas, quienes empíricos o académicos, agremiados o totalmente independientes, han hecho del arte su fuente de sostenimiento y su forma de vivir.

\section{Conclusiones}

La distinción existente en legislaciones como las del Reino Unido entre las categorías de trabajador y empleado da cuenta de la complejidad que comporta la interpretación restrictiva de las regulaciones concernientes a la protección de derechos laborales cuando se pretende aplicarla a la actividad de los artistas, pues éstos, aunque encontrándose en alto grado de dependencia con relación a determinado empleador, se reservan cierta discrecionalidad necesaria para el desarrollo creativo. Por otra parte, aun cuando se haga uso de alguna tipología contractual distinta a la laboral, la prestación personal del servicio de artista, debido a una dependencia económica, debería ser suficiente para considerarlo como un trabajador y no sólo como un prestador de servicios independiente.

La industria creativa como una apuesta para el fortalecimiento de las economías de los países, reivindica la percepción que para estos efectos se ha sostenido en torno al arte y la cultura, en tanto se ha podido evidenciar que en los últimos años este sector ha tenido una participación destacable en el PIB de países como Colombia con un incremento sostenido.

Una de las particularidades de las actividades que conforman la industria creativa, es que el capital humano es imprescindible, pues como se ha dicho, la creación artística es una facultad exclusiva del ser racional.

Por tal razón, siendo el artista el proveedor indiscutible de los contenidos que justifican que tal industria sea denominada cultural o creativa, éste debe gozar de condiciones apropiadas que le permitan beneficiarse de la creación intelectual que realiza de forma profesional. 
Lo anterior implica que el artista reciba una compensación proporcional al aporte que le hace a la industria y que se limiten las disposiciones abusivas sobre sus derechos de autor o conexos en virtud de una eventual relación de subordinación o un contrato de prestación de servicios. Así mismo, las condiciones laborales de los artistas deben ser ajustadas y reguladas en atención a la naturaleza de su disciplina, de tal forma que no se les excluya de la protección laboral existente, por una parte, ni se limite su actividad creativa por la otra.

A su vez, un incentivo real para la producción de contenido creativo de calidad profesional es brindarle al artista la posibilidad de acceder a un tratamiento tributario particular o exceptivo, toda vez que podría afirmarse que el Estado percibe beneficios indirectos derivados de esta actuación individual.

\section{Agradecimientos}

Los autores agradecen a la Vicerrectoría Académica y al Programa de Derecho de la Universidad del Magdalena por concedernos el espacio y demás facilidades para la elaboración del presente artículo. Así mismo, agradecemos al abogado Carlos Andrés Caballero por su valioso aporte en la revisión del manuscrito. AMDG.

\section{Referencias Bibliográficas}

AlL. (2019). Ley del actor fue aprobada en comisión del Senado y pasa a último debate en plenaria. http://ail. ens.org.co/noticias/ley-del-actor-fue-aprobada-en-comision-del-senado-y-pasa-a-ultimo-debateen-plenaria/

Aldana, J. (2014). Colectivos artísticos en Bogotá. La transformación del quehacer artístico entre 1950 y 1970 promovida por El Búho y La Casa de la Cultura. In Cuadernos de Musica, Artes Visuales y Artes Escenicas (Vol. 9, Issue 2, pp. 193-214). https://doi.org/10.11144/Javeriana.mavae9-2.cabt

Davidov, G. (2005). Who is a worker? In Industrial Law Journal (Vol. 34, Issue 1, pp. 57-71). https://doi. org/10.1093/ilj/34.1.57

Fajardo de Rueda, M. (2000). Manuel Dositeo Carvajal y el nacimiento del paisaje en Colombia. Ensayos. Historia y Teoría Del Arte, 1(6), 95-115.

FEDESARROLLO. (2019). Importancia De Las Industrias Creativas En La Economía. Informe Mensual Del Mercado Laboral, 12. https://www.fedesarrollo.org.co/sites/default/files/iml_junio2019_digital.pdf

Fonseca Reis, A. C. (2008). Economía creativa: como estrategia de desarrollo: una visión de los países en desarrollo. In Itaú Cultural.

Gomes, C., \& Elizalde, R. (2009). Trabajo, tiempo libre y ocio en la contemporaneidad. Contradicciones y desafíos. Polis. Revista Latinoamericana, 22. https://doi.org/10.4067/S0718-65682009000100015

Lena, J. C., \& Lindemann, D. J. (2014). Who is an artist? New data for an old question. Poetics, 43(1), 70-85. https://doi.org/10.1016/j.poetic.2014.01.001

MINCULTURA. (2008). ¿Quiénes Somos? https://www.mincultura.gov.co/planes-y-programas/programas/ programa-nacional-estimulos/Paginas/2008-09-23_1724.aspx

Muñoz Martínez, R. (2006). Una reflexión filosófica sobre el arte. Thémata: Revista de Filosofía, 2(36), 239-254. 
Rodríguez, P. (2015). La familia en la pintura colombiana del siglo XIX. Credencial Historia. https://www. banrepcultural.org/biblioteca-virtual/credencial-historia/numero-311/la-familia-en-la-pinturacolombiana-del-siglo-xix

Tarazona, O. (2016). Ramón Torres Méndez: La imagen del pueblo en la primera edición de sus láminas costumbristas 1851-1852. https://expeditiorepositorio.utadeo.edu.co/bitstream/ handle/20.500.12010/2692/Ramon Torres Mendez La imagen del pueblo en la primera edicion de sus laminas costumbristas 1851 . pdf? sequence $=1 \&$ isAllowed $=y$

Throsby, D. (1992). Artists as Workers. In Cultural Economics (pp. 201-208). https://doi.org/10.1007/978-3-64277328-0_20

Throsby, D. (2001). Defining the artistic workforce: The Australian experience. Poetics, 28(4), 255-271. https:// doi.org/10.1016/S0304-422X(01)80003-6

Throsby, D., \& Ginsburgh, V. (2014). Handbook of the Economics of Art and Culture. In Elsevier (1st ed.). https://doi.org/10.1016/B978-0-12-385237-3.00016-5

UNESCO. (2010). Políticas para la creatividad: Guía para el desarrollo de las industrias culturales y creativas. Unesco, 152. http://www.lacult.unesco.org/docc/UNESCO_Guia_por_una_economia_creativa.pdf

Vásquez, W. (2014). Antecedentes de la Escuela Nacional de Bellas Artes de Colombia 1826-1886: de las artes y oficios a las bellas artes. Cuadernos de Música, Artes Visuales y Artes Escénicas, 9, 35-57. https:// doi.org/10.11144/Javeriana.MAVAE9-1.aenb

Velasco, P. (2004). ¿Por qué el ser humano crea obras artísticas? Archivos de Neurociencias, 9(4), 245-253. 